Afrika Focus, Vol. 9, Nr. 1-2, 1993, pp.125-142

\title{
DE BERBERSE IDENTITEIT EN HET NIEUWE MEERPARTIJENSTELSEL IN ALGERIJE
}

\section{Dirk BEKE}

Faculteit van de Rechtsgeleerdheid (RUG), Universiteitstraat 4, B-9000 Gent, België.

\section{SUMMARY}

\section{BERBER IDENTITY AND THE NEW MULTI-PARTYISM IN ALGERIA}

The article first argues that the present population of Algeria can be designed as Arabo-Berber and Berber. The original inhabitants, collectively identified by most historians as Berbers, formed no physical ethnic unity, but they had a common Berber language and culture. The Islamisation of the population of North Africa proceeded faster and became almost general, this in contrast to the slower and more limited Arabisation. The physical-ethnic process of Arabisation by settlement and fusion was altogether restrained. The Arabisaiton was essentially a cultural process (language, popular culture, customs, politics, science, arts).

About one fourth of the present Algerians resisted to (entire) Arabisation. They are living in, or originated from mountain or desert regions (Kabyles, Shawiya, Mozabites, Touareg). Since independence the official policy of Arabisation, against the strong influence of the French language, referred exclusively to Arabic character of the nation. All expressions of the Berber identity, culture and language were oppressed.

Since 1980, a growing cultural revival, mainly among the Kabyles, reacted to this policy. The movement was rather cultural than political. The Berber speaking Algerians seem involved into many other regional and national alliances. With the introduction of the multi-partyism, in 1989, two 'Berber' political parties became active: the FFS (Front des Forces socialistes) and the RCD (Rassemblement 
pour la Culture et la Démocratie). Both parties claim to be national parties and insist on defending, besides the recognition of the Berber identity and culture, general political options (socialism, democracy etc.). Electoral results, however, show that their support comes essentially from different factions of the Berber speaking population.

It is obvious that the Berber ethnicity is used to gain electoral backing. Besides, today the two 'Berber' parties represent the strongest opposition to the Islamic (= Arabic) fundamentalist party, the FIS (Front islamique de Salut), because of their resistance to social, cultural and political intolerance. Secessionist ideas based on Berber ethnicity live only among a small - but well-organised - minority. At the end of 1992, the Berber ethnicity is in Algeria primarily an element of cultural and regional recognition and only secondary an element of political coherence. Finally, Berber ethnicity has also invalidated the official political myth of the homogeneous Algerian Arabic ethnicity.

KEY WORDS: Algeria, Arabs, Berbers, ethnicity, Islam, political parties

\section{Inleiding}

De bedoeling van de volgende bespreking is enerzijds na te gaan hoe sterk 'etniciteit' (of een aantal elementen van dit zeer ruime begrip) de vorming en de groei van de nieuwe politieke partijen recent in Algerije heeft beïnvloed; anderzijds zal ook onderzocht worden in welke mate in de huidige politieke strijd in het land etnische identifikatie gebruikt wordt door de politieke groepen en leiders tot machtsverwerving. Vooraf zal 'etniciteit' in de Algerijnse historische, kulturele en sociale kontekst bekeken worden.

Eind 1991 heeft in Algerije een eerste ronde van nationale verkiezingen plaatsgehad. Het overweldigend sukses van de islamistische partij, het FIS, was de direkte reden, begin 1992, voor de stopzetting van dit verkiezingsproces, het ontslag van president Chadli Bendjedid en een machtsgreep door het leger samen met enkele burger-politici. Terwijl de aktuele ontwikkelingen in Algerije zich in snel tempo voltrekken, zodat het onmogelijk is om in dit artikel up-to-date te zijn, tekent zich als konstante in dit proces de artikulatie van een Berberse identiteit af. Op dit laatste verschijnsel zal in mijn betoog de nadruk liggen.* 


\section{Etnische gebondenheid, kultuur en taal van de Algerijnse bevol- king}

Over de oorsprong van de Noordafrikaanse bevolking bestaat in de literatuur heel wat diskussie (1). Ook het begrip etniciteit wordt sterk verschillend geïnterpreteerd zowel door de Noordafrikaanse bevolking zelf als door westerse antropologen en sociologen met betrekking tot de Noordafrikaanse bevolking. Daarbij is veel spraakverwarring ontstaan omdat elementen zoals taal (Arabisch), kultuur, godsdienst (islam) en (vermeende) fysisch-antropologische afkomst lukraak door elkaar gebruikt worden. Het is niet de bedoeling om met deze uiteenzetting op alle facetten van deze problematiek in te gaan; er zullen alleen enkele elementen belicht worden die voor de etniciteitsfaktor vandaag in Algerije belangrijk zijn. Daarbij zal de nadruk gelegd worden op het onderscheid tussen fysisch-antropologische etniciteit (in de betekenis van biologische afkomst) en elementen van kulturele etniciteit (godsdienst, taal, sociale strukturen, gewoontes enz.). De beklemtoning van de twee elementen, taal en afkomst, is gebaseerd op wat vandaag in Algerije tot uitdrukking komt zowel in publikaties van de intelligentia als in manifestaties en eveneens in talrijke gesprekken die ik met Algerijnen en Algerijnse Berbers had.

Vóór de inval van de Arabieren (7de eeuw) leefden op het Algerijns grondgebied verschillende bevolkingsgroepen met een gemeenschappelijke Berberse taal en kultuur. Wanneer hier de term 'Berbers' gebruikt wordt dan duidt dit op die verschillende volksgroepen (etnische groepen) wegens een gemeenschappelijke kultuur, zonder dat deze groepen onderling een fysisch-antropologische eenheid vormden (2). Na de verovering door de Arabieren (hun aantal wordt op 150.000 geschat) heeft een deel van de Berberse bevolking zich vermengd met de nieuwe bewoners zodat men nu fysisch-antropologisch van Arabo-Berbers spreekt. In het zuiden leven een aantal, meestal vermengde, afstammelingen van zwart-Afrikaanse slaven; in de steden is er een kleine etnische invloed geweest vanwege de Turken. De Europese bevolking, die vóór de onafhankelijkheid ongeveer één miljoen personen telde, is teruggevallen op minder dan 50.000 .

Tot vandaag kennen de verschillende volksgroepen in Algerije een grote onderlinge regionale en etnische solidariteit, die vaak boven de nationale belangen wordt gesteld (3). Verder bestaat er binnen die volksgroepen een nog sterker familieen clangeest (4). Het informeel sociaal kontakt beperkt zich dan ook vaak tot clan- of volksgenoten. Bijgevolg worden huwelijken meestal binnen de sociale kontekst van het dorp of de clan gesloten. 
Op het huidige Algerijns grondgebied woonden vóór 650 noch Arabieren noch islamieten. De gemeenschappelijke taal was, zoals reeds gezegd, het Berbers; de godsdiensten waren het christendom, het jodendom en lokale religies. $\mathrm{Na} 650$ moeten we een onderscheid maken tussen islamizering en arabizering. Hoewel beide nauw met elkaar verweven zijn omdat de islam bij de Arabieren is ontstaan en vooral door hen is verbreid, wijst onder meer Gabriel Camps terecht op het belang van dit onderscheid; hij noemt het eerste een religieus en het tweede een etno-sociologisch proces (5). Een andere auteur, Christiane Souriau, beschrijft het verschil heel gevat als volgt:

'L'islamisation, c'est la reconnaissance du message coranique et l'adoption du système de valeurs et du mode d'organisation en société musulmane qui en découle. L'arabisation, c'est l'adoption d'une langue nouvelle - parlée et/ou écrite - et d'une culture dont elle est le moyen d'expression. Celle-ci se présente sous deux formes: d'une part, la culture populaire, les coutumes et le mode de la vie quotidienne; d'autre part, la culture écrite religieuse, juridique, scientifique ou littéraire' (6).

De islamizering is relatief snel gebeurd, en bijna algemeen. De arabizering daarentegen was duidelijk trager en minder algemeen dan de islamizering. De arabizering heeft eerst in de steden plaats gehad, en heeft zich pas vanaf de 12de eeuw naar de vruchtbare vlakten en de noordelijke nomaden groepen verbreid. Een opvallend detail daarbij is dat sommige gearabiseerde families een fiktieve genealogie vanuit Arabië hebben opgebouwd (7). Tot vandaag zijn allerlei Berberse elementen terug te vinden in de kultuur, het sociale leven en de (volks-)religie in Algerije, ook onder het gearabizeerde deel van de bevolking.

Bij de islamizering moet ook vermeld worden dat aanvankelijk veel Berbers de ('dissidente') Khareditische of Ibaditische islam aangenomen hebben. Historici interpreteren dit dat deze Berbers in het Ibadisme een middel zagen om de arabizering en de afbouw van hun eigen Berberse politieke strukturen tegen te houden (8). De verovering door soennitische heersers vanuit Arabië en het opdringen van het soennisme heeft inderdaad de arabizering versterkt, en niet alleen in de taal en kultuur maar ook in de politieke strukturen. Vandaag zijn alle Algerijnen soennitische moslims (met uitzondering van het kleine restant Ibaditische Berberofonen, de Mozabieten, wonende in, of afkomstig uit, de woestijn-stad Ghardaïa en omgeving.

In de loop der eeuwen is het Arabisch bijna overal in Algerije als geschreven kultuurtaal aangenomen. De Berberse taal is teruggedrongen door het Algerijns-Arabisch, dat nu door de meerderheid van de bevolking wordt gesproken. Toch 
heeft nog zeker één vijfde van de bevolking een Berbers dialekt als dagelijkse omgangstaal (9), met andere woorden ongeveer 5 miljoen op de 25 miljoen inwoners. De Berberofone bevolking is verdeeld in verschillende Berberse subkulturen die onderling sterk verschillen (10). De Berbertalige groepen in het Algerije na de onafhankelijkheid (1962) zijn: de Kabyliërs (afkomstig van de Kustatlas ten oosten van Algiers), de Chewia (afkomstig uit de Aures, in het oosten) de Mozabieten (afkomstig uit de streek van Ghardaïa) en de Toearek (in het zuiden).

‘... On constate par endroits et sous diverses formes la permanence de la langue des berbérophones, soit dans le cadre d'un bilinguisme berbère-arabe, soit dans celui d'un trilinguisme berbère-arabe-français, qui a son origine dans l'époque coloniale, soit enfin dans les régions les plus isolées (montagnes, désert, villages d'où les hommes sons absents parce qu'ils ont émigré à la recherche du travail salarié (11), en tant que langue unique' (12).

In de $19 \mathrm{e}$ en $20 \mathrm{e}$ eeuw is deze taalkundige situatie ingewikkelder geworden door de opkomst van een kategorie tweetaligen, in het Frans en het Berbers, die het produkt is van kolonisatie en emigratie. Tijdens de Franse kolonisatie werden het gesproken Algerijns-Arabisch en vooral de geschreven Arabische kultuurtaal teruggedrongen. De Arabische geschreven taal werd in het bestuur, de handel en het onderwijs bijna totaal vervangen door het Frans. Arabisch werd slechts op enkele scholen als een vreemde taal aangeleerd. Het gesproken Arabisch bleef in gebruik, vooral op het platteland; zelfs een meerderheid van Europeanen die buiten de steden woonden, gebruikten vóór 1930 deze volkstaal (13). Het was vooral in de grote agglomeraties dat de gesproken taal, het Algerijns-Arabisch of het Berbers, geheel of gedeeltelijk vervangen werd door het Frans.

'En effet, le français devenait souvent la "langue du pain", c'est-à-dire la langue du travail du manoeuvre salarié. Les Algériens dépossédés, incorporés dans l'armée coloniale, l'usine, les domaines des grands propriétaires terriens, ou les postes subalternes de la fonction publique, apprenaient un français qu'ils ne maîtrisaient pas toujours, créant un sabir franco-arabe...' (14).

Een reaktie tegen deze kulturele verdrukking kwam omstreeks 1925 vanwege een groep intellektuele Arabofonen, georganiseerd in onder andere de Association des Ulama Réformistes (15). Slogans zoals 'l'islam est ma religion, l'Algérie est ma patrie, et l'arabe ma langue', werden overgenomen tijdens de gewapende nationalistische strijd. Sinds de onafhankelijkheid kwam er een sterk doorgevoerde arabizering in het openbaar bestuur en het onderwijs. Arabisch is de enige nationale taal. Toch blijft Frans, ook in de administratie, belangrijk als tweede taal, vooral voor de kontakten met West-Europa (m.n. Frankrijk). 
Tabel 2: Schema van de fysisch-antropologische groepen en taalgroepen in Algerije

\section{FYSISCH-ANTROPOLOGISCHE GROEPEN}

Arabo-Berbers

Berbers - Kabyliërs

- Chewia

- Mozabieten [n.b. behoren tot de Ibaditische islam]

- Toearek (enkelvoud: Targui)

In klein aantal - afstammelingen van zwart-Afrikaanse etnische groepen

- Europeanen (Fransen, Spanjaarden, Italianen, Maltezers)

- afstammelingen van Turken.

\section{TAALGROEPEN}

Algerijns-Arabisch: Arabo-Berbers en gearabizeerde Berbers

- een deel van hen heeft het Frans als geschreven kultuurtaal

Berberse taal (Tamazight) met als dialekten:

Chewia

Kabylisch

Mozabietisch

Tamahak (Toearek)

- velen kennen ook Arabisch en/of Frans en hebben Arabisch en/of Frans als geschreven kultuurtaal.

- sinds 1990 wordt in Kabylië door de plaatselijke overheden opnieuw het Tifinar, de geschreven taal van het Berbers, naast het Arabisch en het Frans gebruikt.

- sommige Toearek hebben Tifinar, als geschreven kultuurtaal, behouden. 
Diagram 1: schematische indeling van de Algerijnse bevolking
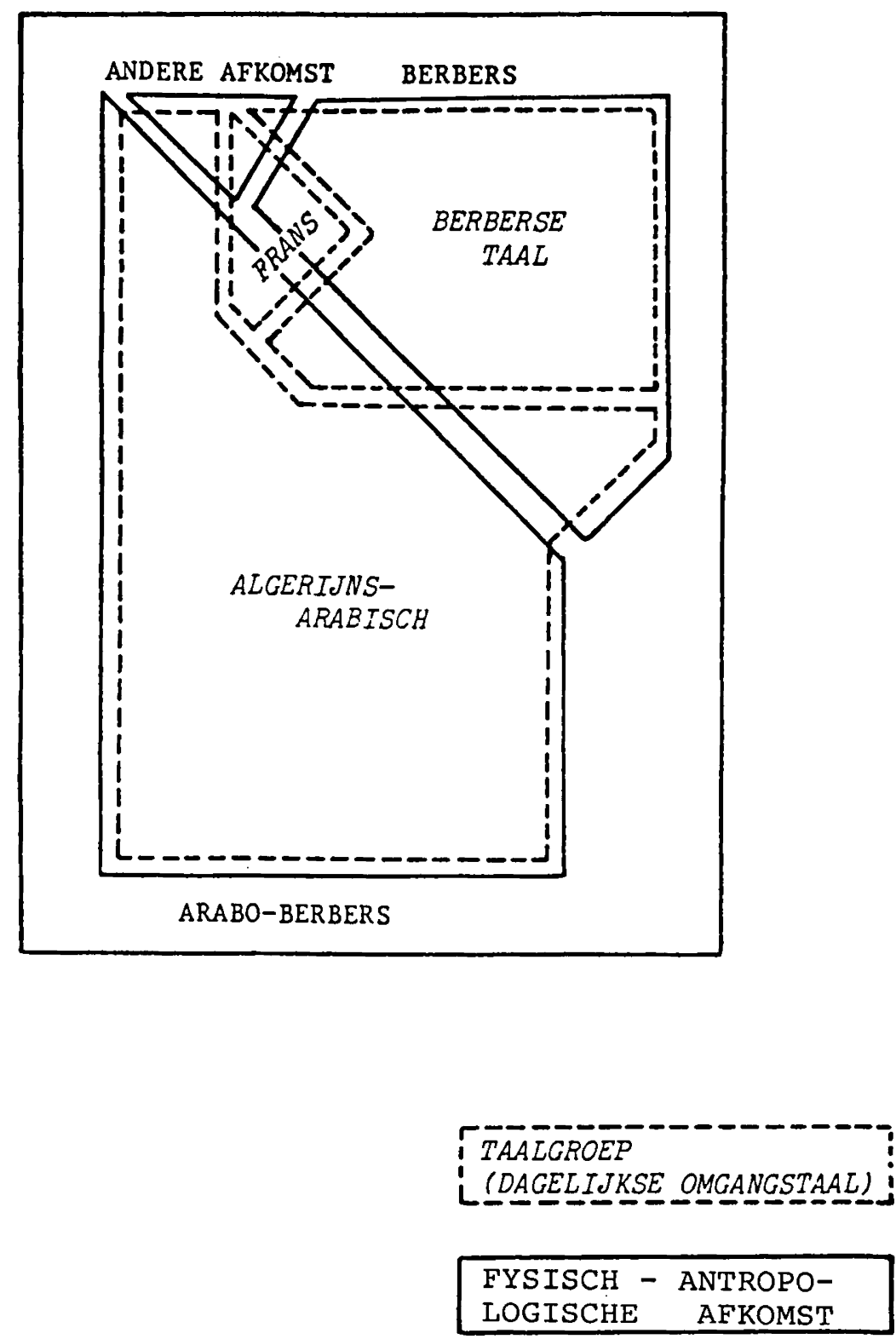
De Berberse taal werd door het nieuwe bewind tot in de jaren tachtig genegeerd of zelfs tegengewerkt; zo werd het geweerd binnen het onderwijs. In het voorjaar 1980 hebben in Kabylië stakingen en manifestaties plaatsgehad, met als inzet eenofficiële erkenning van de Berberse kultuur. Ondanks de omvang van het protest heeft de regering slechts schoorvoetend toegevingen gedaan. In dezelfde periode is ook de eis geuit tot erkenning van alle 'volkstalen', dus ook het Algerijns-Arabisch.

Algemeen kunnen we stellen dat als Algerijnen beweren dat Algerije een Arabisch land is, zij niet op de fysisch-antropologische etniciteit van zijn bevolking duiden, maar op hun gebondenheid met de Arabische wereld via de islam en arabizering. Deze begrippen hebben een sterk emotionele lading omdat zij belangrijke identifikatie-elementen zijn geweest in de strijd tegen Frans-koloniaal Algerije. Tegenwoordig wordt de Arabisch-sprekende bevolking betiteld door de Berberofonen (en hier duidt men speciaal op de taalgroepen) als 'Arabieren'. Deze taalkundige klassifikatie wordt veelal vermengd met fysisch-antropologische afkomst: deze 'Arabieren' zijn in vele gevallen gearabizeerde Berbers (16). Deze etnische tweedeling werd versterkt door de koloniale overheid:

'Les berbères algériens tenus pour plus assimilables parce que dit-on "superficiellement islamisés" (17) devaient bénéficier de toutes sortes de mesures favorables. (...) Il s'agissait surtout d'éviter "que les deux peuples de l'Algérie ne s'habituent au contact l'un de l'autre" '(18).

Ondanks deze bevoorrechte positie in de koloniale periode, begon de onafhankelijkheidsstrijd tegen de Fransen in de bergstreken (Kabylië en de Aures), waar veel Berberofone Berbers wonen (19). De Berberse identiteit en taal werden zelfs door menig Berbertalig vrijheidsstrijder in die tijd opzij geschoven ten voordele van het Arabisch-islamitisch nationalisme.

Het nieuwe Algerijnse bewind heeft geprobeerd de Berbertaligen zo vlug mogelijk te integreren in de Algerijnse staat door een verregaande arabizering in te voeren in het openbaar leven en het onderwijs. Doel was om de nationale solidariteit en eenheid te versterken. Het gevolg was dat de Berberse taal en kultuur van - zoals reeds gezegd - ongeveer één vijfde van de bevolking (20), in de verdrukking kwam. Ook het Berbers gewoonterecht heeft moeten wijken voor het nationale recht, dat voor een deel gebaseerd is op het islamitisch recht.

Toch bestaan de spanningen op de eerste plaats niet tussen Berberofonen en Arabofonen maar veeleer tussen kleinere groepen, ook binnen beide taalkundige kategorieën, wegens sterke etnische (b.v. de Mozabieten), lokale en zelfs verwant- 
schappelijke banden. Wegens de grote verscheidenheid van deze relatief kleine groepen oefenen ze op het nationale vlak weinig politieke invloed uit (21). Dit wil evenwel niet zeggen dat de lokale, etnische en verwantschappelijke gebondenheid geen grote gevolgen zou hebben op sociaal gebied; voor het begrijpen van lokale en regionale politieke verhoudingen, zal men deze clan-gebondenheid zeker niet uit het oog mogen verliezen (22).

De arabizering in Algerije is er niet zozeer op gericht geweest om de zeer kleine minderheid, die Frans als gesproken omgangstaal had, het Arabisch als omgangstaal aan te leren, maar wel de vervanging in het openbaar leven van de Franse kultuurtaal (vooral geschreven taal) door de Arabische kultuurtaal. Het bewind wilde onder de Algerijns-Arabisch sprekende bevolking èn onder de Berberofonen een gemeenschappelijk neo-klassiek Arabisch verbreiden.

\section{De nieuwe politieke kontekst sinds 1989}

In januari 1989 besloot president Chadli Bendjedid af te stappen van de socialistische doctrine, en toe te geven aan de groeiende eisen voor een meerpartijenstelsel. Er kwam voor de Algerijnse republiek een hervorming van het regime met de afkondiging van een nieuwe grondwet. Meest opvallend is dat de term 'socialisme' geheel verdwijnt uit de grondwettekst. Daarnaast zijn een aantal rechten en vrijheden versterkt, zoals persvrijheid en vrijheid van vereniging. In de opsomming hiervan staat, weinig opvallend, ook uitdrukkelijk de vrijheid vermeld om politieke verenigingen op te richten. Deze schuchtere bewoordingen betekenen dat voortaan politieke partijen buiten het FLN kunnen worden erkend. In de grondwet wordt verder uitdrukkelijk vermeld dat alleen Arabisch de nationale taal is; geen enkele verwijzing wordt gemaakt naar de Berberse kultuur of taal.

Op het ogenblik van de eerste lokale verkiezingen onder het nieuwe meerpartijenstelsel, in juni 1990, waren meer dan twintig politieke partijen erkend. Het ministerie van binnenlandse zaken heeft de wet op de politieke verenigingen daarbij duidelijk zeer ruim geïnterpreteerd: de wet verbiedt onder meer politieke verenigingen die uitsluitend gebaseerd zijn op een geloofsovertuiging, en toch zijn islamitische fundamentalistische partijen erkend. Dezelfde wet verbiedt eveneens politieke verenigingen uitsluitend gevestigd op taal- of regionale basis.

Een aantal partijen waren niet nieuw maar doken op uit de illegaliteit. De voornaamste is het socialistische Front des Forces socialistes (FFS) van de 'historische' FLN-leider uit Kabylië, Hocine Ait Ahmed. De belangrijkste nieuwe partij is 


\section{TABEL 1}

Resultaten eerste ronde parlementsverkiezingen december 1991

\begin{tabular}{|c|c|c|c|}
\hline partij & Aantal stemmen & $\%$ ingeschr.kiezers & aantal zetels \\
\hline FIS & 3.260 .222 & $24,59 \%$ & 188 \\
\hline FLN & 1.612 .947 & $12,17 \%$ & 16 \\
\hline FFS & 510.661 & $3,80 \%$ & 25 \\
\hline Onafhankelijken. & 309.264 & $2,33 \%$ & 3 \\
\hline RCD & 200.267 & $1,51 \%$ & 0 \\
\hline andere & 1.004.358 & $7,58 \%$ & 0 \\
\hline Blanco/ongeldig & 024006 & 6070 & \\
\hline Blanco/ongeldig & $\begin{array}{r}924.096 \\
\end{array}$ & $6,97 \%$ & \\
\hline Samen & 6.360 .925 & $47,97 \%$ & \\
\hline \multicolumn{3}{|c|}{ Nog toe te wijzen zetels na de tweede ronde } & 198 \\
\hline
\end{tabular}

Fontaine 1990: 127-128 
het Front islamique de Salut (FIS) van de islamitische fundamentalisten, geleid door Abassi Madani. Een andere nieuwe partij die qua aanhang uitsteekt boven de rijke schakering kleine partijtjes, is de Rassemblement pour la Culture et la Démocratie (RCD), met als hoofd Saïd Saadi, die een moderne laïciserende sociaal-demokratie propageert (met vrouwenemancipatie) en erkenning vraagt van de eigen (volks)kulturen; deze partij bezit reeds een goede basisstruktuur bij de Kabylische Berbers.

Kort vóór de lokale verkiezingen waren de meeste politieke waarnemers het er over eens dat de voornaamste partij van de aanhangers van de islam, of 'islamisten' zoals ze zichzelf graag noemen, het Front islamique de Salut (FIS), een geduchte tegenstrever zou zijn voor het FLN. Weinigen hadden evenwel zo'n overweldigende overwinning van het FIS verwacht. In de meeste steden en provincies behaalde het FIS een meerderheid van de stemmen. Alleen in de streek van de Kabylische Berbers won de Berbergezinde en gelaïciseerde Rassemblement pour la Culture et la Démocratie (RCD) het meestal van het FIS, en in het zuiden bleven een aantal gebieden in handen van het FLN. Deze uitslag is niet in alle streken een getrouwe afspiegeling van de politieke voorkeur van de bevolking. Het Front des Forces socialistes (FFS), van Ait Ahmed, heeft niet deelgenomen heeft aan de lokale verkiezingen, omdat er volgens de partijleiding onvoldoende tijd en waarborgen waren om zich goed te kunnen voorbereiden; de partij heeft daarom opgeroepen tot een boycot van de verkiezingen (23). Uit de kiescijfers blijkt dat éénderde van de kiezers niet is komen stemmen en dat in de twee voornaamste departementen van Kabylië deze onthoudingen oplopen tot drievierde van het aantal kiesgerechtigden (zie tabel 1)(24).

Ondanks de vele pogingen van het bewind om de eerste vrije nationale parlementsverkiezingen, van eind december 1991, naar zijn (FLN) hand te zetten, liet ook bij deze verkiezingen de eerste ronde een overweldigend sukses zien voor het FIS; bovendien bleek dat qua zetelaantal het FFS van Ait Ahmed (dat nu wel deelnam) de tweede partij werd (vóór het FLN). Een ontleding van de kiesresultaten leert ons dat ongeveer éénvierde van de kiesgerechtigden voor het FIS gestemd hebben maar ook dat bijna de helft van de kiesgerechtigden niet is komen stemmen of blanco of ongeldig gestemd heeft (25). Het FLN hoopte, als enig alternatief tegen het fundamentalisme, toch nog veel kiezers te winnen maar heel veel Algerijnen bleken zich nog liever te onthouden. Voor een groep was er duidelijk wèl een alternatief, namelijk voor de Berbertaligen: zij bezorgden grote lokale overwinningen aan het FFS, en in mindere mate ook aan de andere 'Berberse' partij, het RCD. 


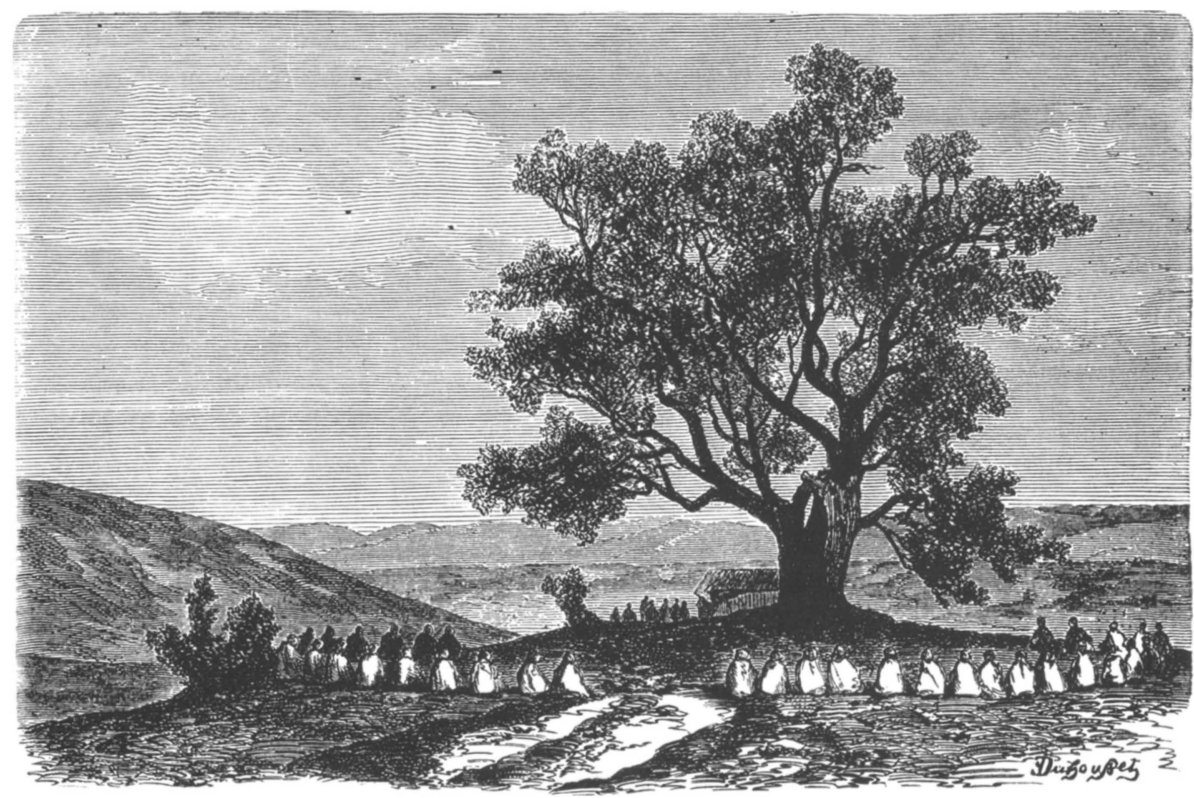

Élections à Koukou (grande Kabylie). - Dessin du commandant Duhousset.

Verkiezingen in Koukou, de vroegere hoofdplaats van 'Groot Kabylië', omstreeks 1860.

Gravure uit: Commandant DUHOUSSET, Excursion dans la Grande Kabylie, notes et croquis receuillis entre la Méditerranée et le Djurjura. In: Le Tour du Monde. Nouveau Journal des Vovages. 1867 deuxième semestre Paris, Hachette, p. 297. 


\section{'Berberse' politieke partijen?}

Bij de opkomst van het Algerijns nationalisme was er tussen 1940 en 1950 een sterke strekking die de Berberse, vooral Kabylische, identiteit wilde bevestigen, en tevens aansluiting zocht bij de tendens tot laïcisering. Tijdens de onafhankelijkheidsstrijd (1954-1962) was er een grote aktiviteit van Kabyliërs binnen het FLN en het bevrijdingsleger, het ALN. Zij ondervonden evenwel veel tegenwerking vooral van de groep rond opperbevelhebber kolonel Houari Boumediene (26). Uiteindelijk moest elke verwijzing naar de Berberse identiteit wijken voor de (Arabische) uniformiteit, die als kultureel instrument werd gezien voor natievorming. $\mathrm{Na}$ de onafhankelijkheid kreeg het Berbers dan ook geen enkele plaats in de officiële politieke doctrine, noch in de praktijk van de politiek, het bestuur of het onderwijs. Taalverscheidenheid werd beschouwd als een groot gevaar voor de eenheid van het land. Berberse identiteitsbevestiging werd een 'subversief' element in Algerije (27). Toen in 1963 de Kabylische guerrilla-leider Hochine Aït Ahmed, met een nieuwe beweging, het FFS, in gewapend verzet kwam tegen de machtskoncentratie van Ben Bella (die de steun had gekregen van Boumediene), werd door de dissidenten sterk benadrukt dat dit geen regionaal (Kabylisch) verzet was. Het FFS beweerde op de eerste plaats de demokratie in het Algerijnse politieke systeem te willen herstellen. De beweging was erg terughoudend over de Berberse kwestie (28). Het is wel duidelijk dat het verzet, dat uiteindelijk begin 1965 volledig werd neergeslagen, uitsluitend gesteund is geweest door Kabyliërs. Hierbij speelde zeker bij een groot aantal sympathisanten mee dat zij zich als 'minderheid' in Algerije bedreigd voelden (29).

Vanaf 1980 is er een opvallende (her)opleving van het Berbers, en dan vooral Kabylisch, bewustzijn in Algerije. We zien een vermenigvuldiging van kulturele verenigingen, radio-uitzendingen in het Kabylisch, bijeenkomsten enz. in Kabylië, maar ook in de Aures (bij de Chewia) en in de Kabylische 'diaspora' (30). Men heeft duidelijk geen schaamte meer om zich als Kabyliër of Berber te manifesteren (31). Sinds de eerste vrije lokale verkiezingen, in 1990, is in de Kabylische gemeentes en departementen door de nieuwe RCD besturen sterke promotie gevoerd voor de Kabylische taal en kultuur. Officiële straatborden in deze regio's zijn drietalig gemaakt: Berbers (Tifinar), Arabisch en Frans. Ook nationaal heeft het Berbers enig spreekrecht verworven; zo is er een kort TV-journaal in het Berbers gekomen. 
Tot 1988 had het FFS, net als alle andere illegale politieke oppositiepartijen in Algerije, nooit een brede volksbasis verworven, noch blijvend aktie kunnen voeren tegen de regering (32). Het FFS heeft zeker ook nooit de gehele Berberse 'beweging' kunnen kontroleren.

Met de invoering van het meerpartijenstelsel, in 1989, is het interessant om de vraag stellen hoe sterk het etnische (en kulturele) element meespeelt binnen de twee zogenaamde 'Kabylische' politieke partijen, het FFS en de RCD. Buiten het FFS en de RCD miskennen alle andere politieke partijen de Berberse eisen. Voor de islamitische fundamentalisten van het FIS, is het gelaïciseerde FFS de voornaamste vijand (samen met de atheïsten en de geëmancipeerde vrouwen) (33).Van hun kant profileren het FFS en de RCD zich duidelijk als nationale (Algerijnse) politieke partijen, maar met een sociale verankering in de lokale Berber samenleving. Taaleisen en kulturele eisen zijn slechts een bijzonder aspekt van een globale politieke stellingname. Het FFS noemt zich gelaïciseerd, demokratisch en socialistisch en zegt zich nooit te hebben willen laten insluiten in een ' Kabylisch getto'. De RCD wil sociaal-demokratisch zijn en geen 'Berberse partij', en legt de nadruk op een nationale inplanting. $\mathrm{Zij}$ willen dus geen Berberse partijen zijn, maar erkennen wel te steunen op de 'sociologische verzuchtingen' in de Berberse regio's. De band met de Berber-bevolking blijkt ook uit het feit dat de FFS leiders grote inspanningen hebben gedaan om van andere Berbertalige groepen, zoals de Chewia, de Mozabieten en de Toearek, kandidaten op hun kieslijsten geplaatst te krijgen (34). Bij de argumentatie voor demokratie wordt ook graag verwezen naar de traditionele Berberse lokale politieke strukturen. In de realiteit hebben beide partijen dus duidelijk een dubbel discours: 'Berbers' voor hun Berberse toehoorders, en voor de anderen een nationaal (Algerijns) politiek discours met enkele vage Berberse eisen (35). In de politieke praktijk steunen zij niet alleen op het taalkundig en kultureel etnische element, maar ook een sterke regionale gebondenheid rond lokale personaliteiten (zoals bijvoorbeeld de strijd tussen FFS en RCD aantoont).

\section{Besluit}

Algemeen kunnen we de stelling (36) bijtreden dat er tot voor kort in Kabylië een algemene samenhang ontbrak onder de intellektuele, kulturele en technokratische elite voor een Berbers etnisch projekt. Het Berbers engagement was lange tijd ook een minderheidsfenomeen onder de Kabylische elite, die in veel andere machtsstrategieën verwikkeld was. De twee 'Berberse' partijen willen nationaal zijn maar vinden, ondanks de dreiging van een FIS regering, nauwelijks aanhang 


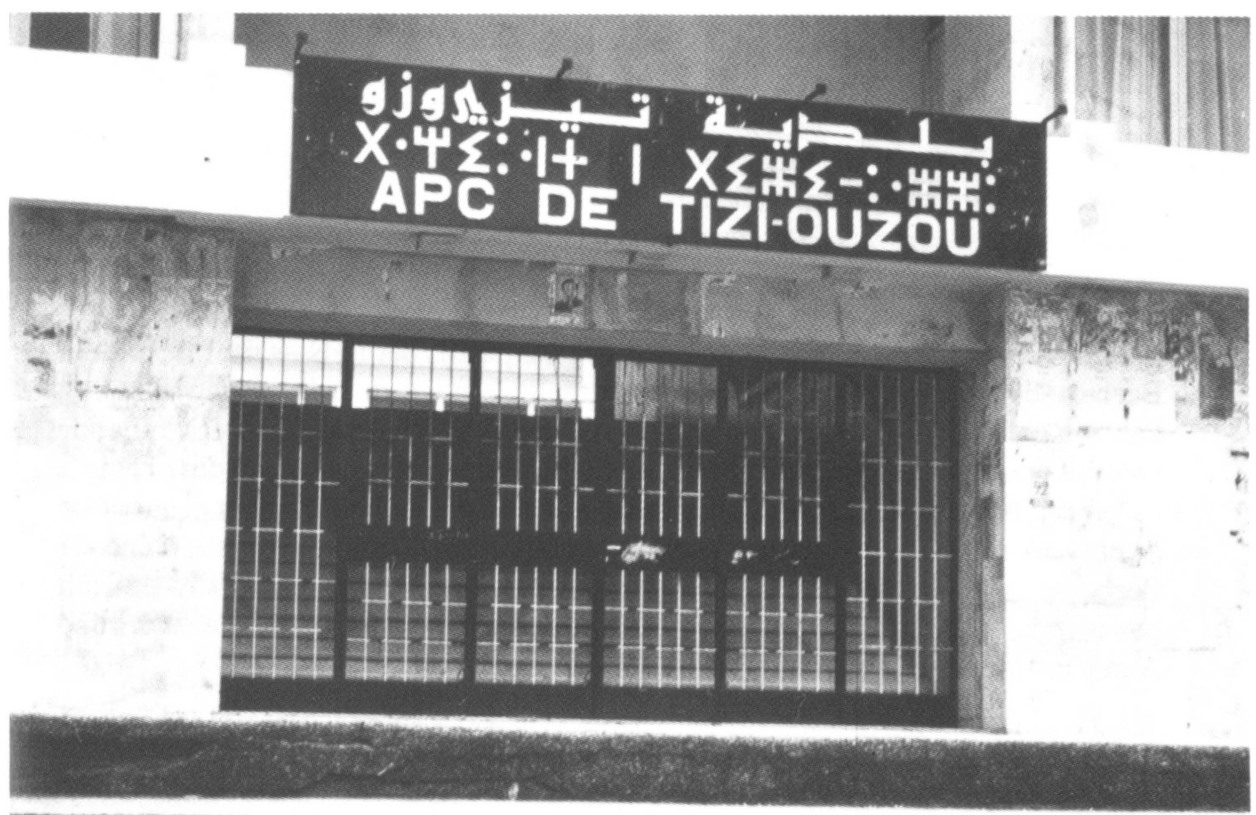

Ingang van de zetel van de 'APC' of 'Assemblée populaire communale' (gemeenteraad) van Tizi-Ouzou, hoofdplaats van Kabylië. Hier behaalde de 'Rassemblement pour la Culture et la Démocratie' (RCD) in juni 1990 de meerderheid. De opschiften zijn in het Arabisch, Berbers (in Tifinar-schrift) en Frans. 
bij de niet-Berbertaligen. Desondanks vormt het FFS een belangrijk politiek tegenwicht (vooral in Algiers) tegen het fundamentalisme (zoals het sukses van hun 'Mars voor de redding van de demokratie' van 2 januari 1992 aantoonde). De leider, Ait Ahmed, kant zich eveneens resoluut tegen de stopzetting van de verkiezingen en het ondemokratische karakter van het huidige Hoog Staatskomitee.

Separatisme leeft op dit ogenblik slechts bij een kleine minderheid, maar een minderheid die goed georganiseerd is. De dreiging van een toekomstig islamitisch, (Arabisch), fundamentalistisch bewind in Algerije heeft duidelijk bij de Berbertaligen het etnisch bewustzijn - zowel in de fysisch-antropologische als in de kultureel-taalkundige betekenis - aangescherpt. De uitbreiding van de Berberse beweging in Kabylië- en deze is ruimer dan de politieke partij, het FFS - naar de andere Berbertalige groepen in Algerije lijkt een realiteit te worden. Deze ontwikkeling kan mogelijkerwijze - onder meer vanwege de geografisch verschillende woongebieden en de grote sociale en ekonomische verschillen tussen deze regio's - het regionaal (Kabylisch) separatisme afzwakken. Wellicht kan het proces ook de eis voor meer bestuurlijke autonomie en kulturele erkenning van de verschillende Berberse regio's versterken. De recente heropleving van het Berbers etnisch bewustzijn heeft in ieder geval de officiële staatkundige mythe van een eenvormige Algerijns-Arabische nationale identiteit doorbroken.

\section{Noten}

* Dit artikel is de gewijzigde tekst van een bijdrage op de workshop 'Etniciteit in Afrika', Leiden, December 1991. In april 1992 heb ik een studiereis kunnen ondernemen naar Algerije waarbij ik onder meer een uitgebreid interview gehad heb met de (Kabylische) leider Hocine Ait Ahmed, voorzitter van het Front des Forces socialistes (FFS). De oorspronkelijke tekst is dan ook met een aantal belangrijke recente gegevens aangevuld.

1. Zie hierover onder meer: Camps 1987: 13 - 39.

2. Bourdieu 1963.

3. Leca \& Vatin 1975: 300.

4. 'Familie' tot in de verre verwantschap; 'clan' als groep van een aantal families maar ook soms een groep van goede bekenden, vaak regionaal.

5. Camps 1987: 132-133.

6. Souriau 1975: 376.

7. Camps 1987: 98.

8. Camps 1987: 99-102. Zie eveneens Quandt 1973: 286.

9. Imazighen Ass-a 1989: 1.

10. Quandt 1972: 285-286.

11. 'Les deux villes où il $\mathrm{y}$ avait le plus de berbérophones sont Alger et Paris'.

12. Souriau 1975: 377. 
13. Marçais $1931 / 1961$.

14. Souriau 1975: 281

15. De Oelama (of Ulama) zijn de theologen en rechtsgeleerden van het islamitisch recht.

16. Imazighen Ass-a 1989: 10.

17. In feite wordt hier eerder bedoeld 'gearabiseerd'.

18. Hermassi 1975: 81; en geciteerd: Berque 1962.

19. Lacoste 1980: 112-181.

20. Etienne 1971: 74.

21. Leca \& Vatin 1975: 301

22. Merghoub 1972.

23. Fontaine 1990: 124-140.

24. Fontaine 1990: 127-128.

25. Fontaine 1992: $155-165$.

26. Imazighen Ass-a 1989: 21-22.

27. Imazighen Ass-a 1989: 12-13.

28. Heggoy 1969: 121-140.

29. Imazighen Ass-a 1989: 23.

30. Imazighen Ass-a 1989: 99.

31. Imazighen Ass-a 1989: 14, 20.

32. Imazighen Ass-a 1989: 30.

33. Imazighen Ass-a 1989: 100.

34. Deze standpunten en akties zijn duidelijk bevestigd in het interview dat ik had met Ait Ahmed, voorzitter van het FFS (Algiers, 19 april 1992).

35. Imazighen Ass-a 1989: 102-103.

36. Zie ook het besluit in: Imazighen Ass-a 1989: 104-105.

\section{Literatuur}

BERQUE, Jacques (1962). Le Maghreb entre deux guerres. Paris, Le Seuil.

BOURDIEU, Pierre (1963). Sociologie de l'Algérie, Paris, PUF.

CAMPS, Gabriel (1987). Les Berbères: Mémoire et identité, Paris, Ed. Errance.

ETIENNE, Bruno(1971). ' Vocabulaire politique et légitimité en Algérie' in: Annuaire de l'Afrique du Nord: 74.

FONTAINE, Jacques (1990). 'Les élections locales algériennes du 12 juin 1990: Approche statistique et géographique' in: Maghreb-Machrek, no. 129, juillet-août-sept.: 124-140.

FONTAINE, Jacques (1992). 'Les élections législatives algériennes: Résultats du premier tour, 26 décembre 1991' in: Monde arabe, Maghreb-Machrek, no. 135, janv/mars: 155 -165 .

HEGGOY, Alf Andrew (1969). 'The F.F.S., an Algerian Opposition to the One-Party System' in: African Historical Studies, II, 1: 121-140.

HERMASSI, Elbaki. (1975). Etat et société au Maghreb: Etude comparative, Paris, Anthropos.

Imazighen Ass-a (Berbères dans le Maghreb contenporain), 1989, Paris/Alger, L'Harmattan/Bouchene.

LACOSTE, Yves (1980). Unité et diversité du tiers monde, III: Foyer révolutionnaires dans les montagnes: Amérique latine-Afrique du nord, Paris, Maspero: 112-181. 
LECA, Jean \& Jean-Claude VATIN (1975). L'Algérie politique: institutions et régime, Paris, Presses de la Fondation nationale des Sciences politiques.

MARÇAIS, William (1961). 'Rapport d'inspection générale' in: L'Enseignement public, revue pédagogique, no. 12, 1930; no. 1-2, 1931 (Hernomen in: Articles et conférences, Faculté des Lettres d'Alger, XXI, 1961: 171-192).

MERGHOUB, Baelhadj(1972). Le développement politique en Algérie: Etude des populations de la région du M'Zab, Paris, A. Colin.

QUANDT, William B. (1972). 'The Berbers in the Algerian Political Elite' in: Arab and Berbers: From Tribe to Nation in North Africa [Ed. by Ernest GELLNER and Charles MICAUD], London, Duckworth.

SOURIAU, Christiane (1975). 'L'arabisation en Algérie' in: Introduction à l'Afrique du Nord contemporaine, Paris, C.N.R.S. 